\title{
Mapping Cabernet Franc vineyards by unmanned aerial vehicles (UAVs) for variability in vegetation indices, water status, and virus titer
}

\author{
Andrew G. Reynolds ${ }^{1}$, Hyun-Suk Lee ${ }^{1}$, Briann Dorin ${ }^{1}$, Ralph Brown ${ }^{2}$, Marilyne Jollineau ${ }^{3}$, Adam Shemrock ${ }^{4}$, Marnie \\ Crombleholme ${ }^{1}$, Emilie Jobin Poirier ${ }^{1}$, Wei Zheng ${ }^{5}$, Maxime Gasnier ${ }^{6}$, Mehdi Shabanian ${ }^{7}$ and Baozhong Meng ${ }^{7}$ \\ ${ }^{1}$ Cool Climate Oenology and Viticulture Institute, Brock University, St. Catharines, Ontario, Canada; ${ }^{2}$ School of \\ Engineering, University of Guelph, Guelph, Ontario; ${ }^{3}$ Dept. of Geography, Brock University, St. Catharines, Ontario; \\ ${ }^{4}$ Air-Tech Solutions, Kingston, Ontario; ${ }^{5}$ Dept. of Agriculture and Food, University of La Rioja, Logroño, La Rioja, \\ Spain; ${ }^{6}$ Agro-Paris-Tech, Paris, France; ${ }^{7}$ Dept. of Cell and Molecular Biology, University of Guelph.
}

\begin{abstract}
The hypothesis of this research was that the maps based on remotely-sensed images would create zones of different vigor, yield, water status, winter hardiness and berry composition and the wines from the unique zones would show different chemical and sensorial profiles. A second hypothesis was that titer of grapevine leafroll-associated virus (GLRaV) could be correlated spatially to NDVI and other spectral indices. To determine zonation, unmanned aerial vehicles (UAVs) with multispectral and thermal sensors were flown over six Cabernet Franc vineyard blocks in Ontario, Canada. Zonation was based on NDVI values, and spatial correlations were examined between the NDVI and leaf water potential $(\psi)$, soil water content (SWC), stomatal conductance $\left(g_{\mathrm{s}}\right)$, winter hardiness $\left(\mathrm{LT}_{50}\right)$, vine size, yield, and berry composition. Additional NDVI data were acquired using GreenSeeker (proximal sensing), and both NDVI data sets produced maps of similar configuration. Several direct correlations were found between UAV-based NDVI and vine size, berry weight, yield, titratable acidity, SWC, leaf $\psi, g_{\mathrm{s}}$, and NDVI from GreenSeeker. Inverse correlations included thermal data, Brix, color/ anthocyanins/ phenols, and $\mathrm{LT}_{50}$. The pattern of UAV-based NDVI and other variables corresponded to the PCA results. Thermal scan and GreenSeeker were useful tools for mapping variability in water status, yield components, and berry composition. In 2016, zoned maps were created based on UAV NDVI data, and grapes were harvested according to the separate zones. Additionally, spatial correlations between GLRaV titer and NDVI were observed. Use of UAVs may be able to delineate zones of differing vine size, yield components, and berry composition, as well as areas of different virus status and winter hardiness.
\end{abstract}

\section{Introduction}

The Ontario wine industry produces $\approx 80,000$ t of grapes and consists of cultivars such as Riesling, Chardonnay, and Cabernet franc as well as Cabernet Sauvignon, Merlot, Pinot noir, and many others (www.grapegrowersofontario.com). Cabernet franc is the most widely planted red wine cultivar. Soils are variable due to widespread glacial activity $>10,000$ years ago, and many vineyards are situated on soils that range widely in texture, depth of solum, and water-holding capacity [1]. This soil variability impacts vine vigor, yield, and water status.

GreenSeeker and other ground-based (proximal) sensing technologies might allow grapegrowers to identify unique zones without use of aircraft through continuous compilation of NDVI data from vine canopies [2-4]. If zones can be identified from the ground, then different zone-based wine products could be created with minimal cost from the producer. Data validation is required to determine relationships between proximallysensed data and agriculturally relevant variables. Proximal sensing is a relatively recent innovation and its evaluation in viticulture is uncommon. Proximal sensing correlated with vine size and berry color in Merlot vineyards in Greece [5] and with downy mildew levels in Italy [4]. Linear correlations to stable isotope contents in leaves $\left({ }^{13} \mathrm{C}\right.$ and $\left.{ }^{15} \mathrm{~N}\right)$ provided evidence that canopy reflectance could detect water and nutritional-based plant stresses [6,7]. Research into proximal sensing has mainly been limited to agronomic crops [8,9] and limited viticulture-related work has occurred in Canada [10-11].
Attempts have been made to identify unique zones by remote sensing (RS) and to associate these remotelysensed regions with vine water status, soil moisture, vine vigor, yield, and berry composition. However, use of aircraft-based RS is costly and in agricultural systems it can be imprecise [5]. Data must be converted to vegetation indices (VIs), e.g., normalized difference vegetative index (NDVI) through appropriate computer software [12-15]. Validation of data acquired by RS is necessary to determine whether ostensibly-unique zones are relevant from a standpoint of physiology, yield, and berry composition. One challenge involved masking of cover crop spectral reflectance from images to assess the vine canopy-specific NDVI and other VIs $[14,15]$.

RS has been used in modelling vegetative growth, and to predict grape composition from those measurements. Remotely sensed multispectral data were used to delineate a Chardonnay vineyard into small-lot production zones based on vine size (pruning weights; vigor), which were related to vine water status and grape composition [16]. Relationships between VIs and vegetative growth were further explored with positive correlations between the VIs and vine size [17]. The ability for RS to predict grape composition variables was explored in Australia, noting that re-sampling to a final pixel size approximately equal to row width, effectively combining vine size and density information into a single pixel, resulted in the strongest correlations to color and phenols [18]. In Languedoc, temporally stable relationships occurred between NDVI-delineated zones and vegetative growth, vine water status, and yield [19]. 
Aircraft-based RS has been proven useful for monitoring vegetative growth, and for making inferences about grape composition from multispectral measurements. In Ontario, NDVI data from RS was associated with numerous variables in Riesling [14,15] and Pinot noir [13] vineyards, including vine water status, yield components, and berry composition. RS was useful to determine Pinot noir anthocyanins and phenols, in addition to water status, yield and vine size [13]. These studies were unique by employing RS in cover-cropped vineyards and thereafter using protocols for excluding the spectral reflectance contributed by inter-row vegetation. Aircraft-based RS has been used to make inferences about grape composition from multispectral measurements [20,21]. However, employment of UAVs for RS in vineyards is a relatively new area of research, heretofore untested in Canada, and capable of acquiring high resolution spatial data without high cost of aircraft. As with proximal sensing there has been little published, and most has confirmed their ability to acquire NDVI and related images [22-24]. Relationships were explored between photosynthesis and chlorophyll fluorescence by hyperspectral imagery captured via UAVs [25]. Significant relationships were demonstrated between photosynthesis and chlorophyll fluorescence vs. remote measurements, and between both chlorophyll $\mathrm{a} / \mathrm{b}$ and leaf carotenoids vs. several VIs based on multispectral images acquired by UAVs [26]. UAVs were also utilized for assessment of vineyard water status by correlation of stem water potential $(\psi)$ with NDVI [27]. Further relationships were elucidated between several VIs [NDVI, photochemical reflectance, renormalized difference vegetation index, red edge inflection point (REIP)] vs. leaf $\psi$ and stomatal conductance $\left(g_{\mathrm{s}}\right)$ [28]. UAV-based NDVI also correlated with levels of Fe chlorosis, leaf carotenoids, and grape leaf and berry anthocyanins [29].

Many vineyards in Ontario, British Columbia, and California are infected by both grapevine leafrollassociated virus (GLRaV) as well as grapevine red blotch virus (GRBV). GLRaV is one of the most destructive diseases in all grape-growing regions globally. Yield losses from GLRaV can reach 20-40\% [30], depending on cultivar, rootstock, soil type, vine age, and climate. Many large Ontario vineyards have attained the designation as "underperforming" by wineries, based primarily on fruit maturity characteristics such as reduced total soluble solids (TSS) and color. Technologies must be developed and implemented to detect zones of virus infection before entire vineyard blocks become unsuitable for quality winemaking. Evidence of correlations between both remotely- and proximally-acquired vegetation indices (VIs) such as NDVI and titer of GLRaV and GRBV, as well as unique spectral signatures of virusinfected vine leaves would be of great benefit.

\section{Materials and methods}

\subsection{Sites and cultivars}

Six Cabernet franc vineyards (1-2 ha) in the Niagara Region were chosen. The sites represented the following sub-appellations: Niagara Lakeshore (Buis), Creek
Shores (Pondview), St. Davids Bench (Chateau des Charmes), Lincoln Lakeshore north (George), Lincoln Lakeshore south (Kocsis), Beamsville Bench (Cave Spring). Soil types [1] varied substantially from welldrained coarse-textured Tavistock and Vineland series (Niagara Lakeshore, Lincoln Lakeshore north), to moderately-well drained Chinguacousy (Creek Shores, Beamsville Bench), and poorly-drained Jeddo (Lincoln Lakeshore south) and Beverly/Toledo soils (St. Davids Bench). These soils provided a range of water-holding capacities that impacted vine water status.

\subsection{Geolocation}

Vineyard blocks were GPS-delineated to determine shape using a Trimble Handheld GPS, equipped with TerraSync software (Trimble Navigation, Sunnyvale, CA). Sentinel vines (80-100) were identified in a $\approx 8 \mathrm{~m} \mathrm{x} 8 \mathrm{~m}$ grid within each vineyard and geolocated by the aforementioned GPS system. Post-collection differential correction was performed using GPS Pathfinder Office (Trimble) to $\approx 30$ $50 \mathrm{~cm}$ accuracy using the Port Weller, ON base station correction. Field measurements and berry samples were taken on these vines in all vintages.

\subsection{Soil moisture, leaf water potential $(\Psi)$, and stomatal conductance $\left(g_{\mathrm{s}}\right)$}

Vineyard soil water content (SWC) was measured by time domain reflectometry (TDR) at a $20 \mathrm{~cm}$ depth using the Field Scout TDR 300 Soil Moisture Meter (Spectrum Technologies, East Plainfield, IL). Measurements took place at berry set, lag phase, and veraison on all sentinel vines. Vine water status was measured using midday leaf $\psi$ by pressure bomb (Soil Moisture Equip., Santa Barbara, CA). Measurements were made on designated leaf $\psi$ vines $(\approx 15-20$ per vineyard block), on the same days as SWC measurements, from 1000h-1400h (ca. solar noon), under full sun. Leaf $g_{\mathrm{s}}$ was measured by a handheld porometer (Decagon Devices, Pullman, WA) on leaf $\psi$ vines.

\subsection{Yield components and vine size}

Harvest dates were at the discretion of vineyard managers. Fruit from each sentinel vine was harvested, cluster number determined, and fruit weighed with a field scale. Cane prunings were weighed to determine vine size.

\subsection{Berry analysis}

A 100-berry sample was taken from each sentinel vine at harvest and frozen at $-25^{\circ} \mathrm{C}$. Samples were weighed to determine mean berry weight, and placed in a beaker in a water bath at $80^{\circ} \mathrm{C}$ for $1 \mathrm{hr}$ to dissolve precipitated tartrates. Samples were homogenized in a juicer and $\approx 35$ $\mathrm{mL}$ were clarified by centrifugation at $4500 \mathrm{~g}$ for 10 minutes. TSS were measured by refractometer (UV, Buffalo, NY); pH with an Accumet $\mathrm{pH}$ meter (Fisher, Mississauga, ON); titratable acidity by titration to an 8.2 $\mathrm{pH}$ endpoint with $0.1 \mathrm{~N} \mathrm{NaOH}$ by a PC-Titrate autotitrator (Man-Tech, Guelph, ON). Remaining juice $(\approx 20 \mathrm{~mL})$ was retained for subsequent color analysis. Absorbances (420 and $520 \mathrm{~nm}$ ) were measured using an Ultrospec 2100 Pro UV-VIS spectrophotometer (Biochrom, Cambridge, UK). Color intensity was calculated as $\mathrm{A}_{420}+\mathrm{A}_{520}$. Total 
anthocyanins were quantified using the $\mathrm{pH}$ shift method [31], and total phenols by Folin-Ciocalteu method [32].

\subsection{Spatial mapping}

GPS coordinates from vineyard blocks and sentinel vines were imported into a GIS environment (ArcGIS 10.3; Environmental Systems Res. Inst., Redlands, CA) and linked to point data collected from sentinel vines. Spatial interpolation techniques (i.e., inverse-distance weighting; Diffusion interpolation with barriers for remotely-sensed data) were applied to these data were used to estimate the values of variables at unsampled locations.

\subsection{Hand-held spectral signatures}

There has been limited experience in measurement of unique spectral signatures in virus-infected vines, including GLRaV [33] and GRBV [34]. Prior to appearance of virus symptoms, spectral reflectance in the visible and near-infrared (NIR) ranges was measured using leaves from virus-free and GLRaV-infected vines. An EPP2000 (UV-Vis-100 nm) spectrometer, controlled by a laptop computer running SpectraWiz software (Stellarnet, Tampa, FL) was used to record reflectance spectra $[13,14]$. A custom-built enclosure was used to hold the leaf and 5-W halogen bulb light source.

\subsection{Proximal sensing}

A GreenSeeker unit (Trimble Navigation) mounted on a four-wheel-drive vehicle was used to collect NDVI data in 2015-2017 on dates close to soil moisture and leaf $\psi$ data collection. Data were imported into Farmworks software (Trimble) and spatial maps created. Shapefiles were then imported into an ArcGIS geodatabase, GPS coordinates identical to the sentinel vines identified, and NDVI data corresponding to these coordinates extracted.

\subsection{UAV and sensors}

\subsubsection{Flights}

The 2015 and 2016 UAV flights corresponded to the veraison SWC, leaf $\psi$, and GreenSeeker data collection. Image acquisition in 2016 was performed consistent to 2015 flights [10]. Two sensors were used for image acquisition. The first operated in the visible and NIR portions of the electromagnetic spectrum (EMS) (MiniMCA 6; Tetracam, Chatsworth, CA) utilizing five spectral bands (blue, green, red, red edge, NIR) equipped with an incident light sensor. The second sensor operated in the thermal-IR portion of the EMS (A65 thermal imaging camera; FLIR Systems, Burlington, ON).

\subsubsection{Image acquisition, pre-processing, processing}

Image acquisition was performed over each vineyard block according to previous protocols [10]. Once assembled and corrected NDVI-red, NDVI-green, REIP, and Normalized Difference Red Edge (NDRE) were calculated on mosaics. Pixel values corresponding to sentinel vines were extracted and compiled into a database including all field based variables (e.g. leaf $\psi$ ).

\subsection{Virus titer determination}

All vines designated for leaf $\psi$ and $g_{\mathrm{s}}$ measurements were sampled September 2016 to determine GLRaV titer.
Total RNAs were isolated from leaf samples using a recently developed method [35]. Total RNAs were used in reverse transcription using primers specific to GLRaV2 and 3, followed by amplification through PCR using broad-spectrum primers to identify virus presence [36]. To determine virus titer for comparison and correlation to the UAV and GreenSeeker data, quantitative qPCR was conducted by Power SYBR Green PCR Master Mix and StepOnePlus qPCR (Applied Biosystems).

\subsection{Data analysis}

Basic linear correlations and regressions were performed on the ground-based, proximally-sensed, and UAV data to determine relationships, particularly those between proximally sensed/UAV data vs. ground-based data using XLStat (Addinsoft, Paris, France). Principal components analysis (PCA) was likewise performed. Maps were created for all variables using ArcGIS. $K$-means clustering and Moran's $I$ were used to verify spatial relationships.

\section{Results and discussion}

\subsection{Principal components analysis}

NDVI data from both GreenSeeker and UAV flights were closely correlated in PCA (Fig. 1A-D). These variables were closely related to vine size, yield components, berry weight, leaf $\psi, g_{s}$, and SWC. In most circumstances NDVI data were inversely correlated to leaf temperature and thermal data obtained from UAV flights. Inverse correlations between NDVI and phenolic analytes (anthocyanins, $\mathrm{OD}_{420+520}$, phenols) were observed. These relationships confirmed 2015 observations [10].

\subsection{Map analysis and hand-held spectrometer}

Spatial variability of most variables was consistent with that observed in 2015 [10]. Patterns of spatial variability in NDVI maps based on GreenSeeker and UAV flights were similar (Fig. 2), suggesting that proximal sensing might be a lower cost alternative to UAV flights. Spatial patterns in UAV-based thermal camera data were opposite to those of both GreenSeeker and UAV NDVI, with high thermal zones associated with low NDVI. Low NDVI zones were likewise associated with low SWC, leaf $\psi$, and leaf $g_{\mathrm{s}}$. Lower NDVI zones also corresponded with low yields, berry weight, and vine size, but higher $\mathrm{LT}_{50}$ values. In most circumstances, low NDVI zones were associated with high levels of $\mathrm{OD}_{420+520}$, anthocyanins, and phenols, as well as Brix and $\mathrm{pH}$, and corresponded to low TA values. Relationships between NDVI vs. soil moisture and leaf $\psi$ have been demonstrated in Ontario with GreenSeeker on Riesling, Pinot noir, and Cabernet franc [11], and by conventional aircraft in Riesling [14-15] and Pinot noir [13]. Similar relationships between canopy reflectance and water status were demonstrated in Greece [7], Languedoc [19] and Spain [27]. Relationships between spectral reflectance and anthocyanins, color, and phenolics have been demonstrated in Pinot noir [11,13] and Cabernet franc $[10,11]$ in Ontario, in Merlot in Greece [5], Tempranillo in Spain, and Cabernet Sauvignon in Australia [18]. Similar relationships were observed in Ontario for Brix vs NDVI in Pinot noir, Cabernet franc and Riesling 
[10,11,13-15] and NDVI vs terpenes in Riesling $[10,11,14,15]$.

Processing UAV data in 2016 into several VIs suggested that NDVI red, NDVI green, REIP, and NDRE index were weakly spatially associated with NDVI in one vineyard (data not shown). Zones in the southern portions of the vineyards appeared inversely associated with NDVI. There were associations between NDVI red, NDVI green, REIP, and NDRE vs. GLRaV titer. These relationships are contrary to prior observations in Cabernet franc where low NDVI was associated with severe GLRaV symptoms [37]. Hand-held spectrometer data showed noteworthy differences between virusaffected and virus-free vines in terms of increased spectral reflectance in the green and NIR bands.

\subsection{Regression analysis}

Only three of six vineyards contained suffient numbers of GLRaV-infected vines to permit statistical analysis. Two of three displayed no relationship with UAV-based NDVI, while a third showed a weakly-positive relationship (data not shown). Four vineyards displayed strong linear relationships between UAV-based and GreenSeeker-based NDVI (data not shown). Several viticultural variables were likewise correlated with UAVbased NDVI (Fig. 1E-H), including SWC (four vineyards; three inverse), leaf $\psi$ (four vineyards), $g_{\mathrm{s}}$ (four vineyards; one inverse), vine size (four vineyards), yield (three vineyards), $\mathrm{LT}_{50}$ (inverse; three vineyards), plus single vineyards with direct NDVI vs. TA relationships, and inverse Brix, $\mathrm{pH}$ and total phenols relationships. Thermal camera data were inversely related to NDVI.

\section{Conclusions}

UAV-derived NDVI data were related to those from GreenSeeker as well as many other variables of viticultural significance, particularly leaf $\psi, \mathrm{g}_{\mathrm{s}}$, vine size, yield, and $\mathrm{LT}_{50}$. There was little relationship between NDVI and GLRaV titer in the six vineyards. Other VIs such as NDVI-red, NDVI-green, REIP, NDRE, and others may be better indicators of virus titer.

\section{Literature cited}

1. M.S. Kingston, E.W. Presant, The Soils of the Regional Municipality of Niagara. Report 60, Ont. Inst. of Pedology, Guelph, ON (1989).

2. R. Drissi, J. Goutouly, D. Forget, J. Gaudillère, Agronomy J., 101, 226 (2009).

3. F. Mazzetto, A. Calcante, A. Mena, J. Agric. Eng., 1, 11 (2009).

4. F. Mazzetto, A. Calcante, A. Mena, P. Sacco, J. Agric. Eng., 2, 1 (2011).

5. S. Stamatiadis, D. Taskos, C. Tsadilas, C. Christofides, E. Tsadilas, J.S. Schepers, Am. J. Enol. Vitic., 57, 415 (2006).

6. S. Stamatiadis, D. Taskos, E. Tsadilas, C. Christofides, C. Tsadilas, J.S. Schepers, Prec. Agric, 11, 306 (2010).

7. D.G. Taskos, S. Koundouras, S. Stamatiadis, E. Zioziou, N. Nikolaou, K. Karakioulakis, N. Theodorou, Proc. Ampelos Conf., Trends in Vitiviniculture Development, Santorini, Greece. http://ampelos2013.conferences.gr/ (2013).

8. D. Barker, J. Sawyer, Agronomy J., 102, 964 (2010).

9. W.C. Bausch, J.A. Delgado, In: T. Van Toai et al. (Eds.), Digital Imaging and Spectral Techniques: Applications to Precision
Agriculture and Crop Physiology (pp. 145-157). ASA Special Publication 66. Madison, WI (2003).

10.A.G. Reynolds, R.B. Brown, M. Jollineau, A. Shemrock, E. Kotsaki, H.-S. Lee, W. Zheng, Proc. 11th Terroir Congress, McMinnville, OR, p. 381 (2016).

11.A.G. Reynolds, R.B. Brown, E. Kotsaki, H.-S. Lee, Proc. 11th Terroir Congress, McMinnville, OR, p. 477 (2016).

12.A. Hall, J. Louis, D. Lamb, Proc. $6^{\text {th }}$ International Conference on Geocomputation; Univ. of Queensland, Brisbane (2001).

13.D. Ledderhof, R.B. Brown, A.G. Reynolds, M. Jollineau, Can. J. Plant Sci., 96, 89 (2015).

14.M. Marciniak, R.B. Brown, A.G. Reynolds, M. Jollineau, J. Int. Sci. Vigne Vin, 49, 1 (2015).

15.A.G. Reynolds, M. Marciniak, R.B. Brown, L. Tremblay, L. Baissas, Prog. Agric. et Vitic., 127(12), 259 (2010).

16.L. Johnson, D. Bosch, D. Williams, B. Lobitz, Appl. Engin. Agric., 17, 557 (2001).

17.S. Dobrowski, S. Ustin, J. Wolpert, Austral. J. Grape Wine Res., 9, 177 (2003).

18.D. Lamb, M. Weedon, R.G.V. Bramley, Austral. J. Grape Wine Res., 10, 46 (2004).

19.C. Acevedo-Opazo, B. Tisseyre, S. Guillaume, H. Ojeda, Prec. Agric., 9, 285 (2008).

20.A. Gitelson, Y. Kaufman, M. Merzlyak, Remote Sensing Environ., 58, 289 (1996).

21.D. Post, A. Fimbres, A. Matthias, E. Sano, L. Accioly, A. Batchily, L. Ferreira, Soil Sci. Soc. Am. J., 64, 1027 (2000).

22.M.L. Guillen-Climent, P.J. Zarco-Tejada, J.A. Berni, P.R. North, F.J. Villalobos, Prec. Agric., 13, 473 (2012).

23.A. Matese, J. Primicerio, F. Di Gennaro, E. Fiorillo, F.P. Vaccari, L. Genesio, Acta Hortic. 978, 63 (2013).

24.D. Turner, A. Lucieer, C. Watson, Proc. 34th Int. Symposium on Remote Sensing of Environment, Sydney, Australia; http://www.isprs.org/proceedings/2011/ISRSE-34/ (2011).

25.P.J. Zarco-Tejada, A. Catalina, M.R. González, P. Martín, Remote Sens. Environ., 136, 247 (2013).

26.P.J. Zarco-Tejada, M.L. Guillén-Climent, R. HernándezClemente, A. Catalina, M.R. González, P. Martín, Agric. Forest Meteorol., 171- 172, 281 (2013).

27.J. Baluja, M.P. Diago, P. Balda, R. Zorer, F. Meggio, F. Morales, J. Tardaguila, Irrig. Sci., 30, 511 (2012).

28.P.J. Zarco-Tejada, V. González-Dugo, L.E. Williams, L. Suárez, J.A.J. Berni, D. Goldhamer, E. Fereres, Remote Sens. Environ., 138, 38 (2013).

29.F. Meggio, P.J. Zarco-Tejada, L.C. Núñez, G. Sepulcre-Cantó, M.R. González, P. Martín, Remote Sens. Environ., 114, 1968 (2010).

30.N. Habili, F.W. Nutter Jr., Plant Disease, 81, 625 (1997).

31.T. Fuleki, F.J. Francis, J. Food Sci., 33, 72 (1968).

32.K. Slinkard, V. Singleton, Am. J. Enol. Vitic., 28, 49 (1977).

33.R.A. Naidu, E.M. Perry, F.J. Pierce, T. Mekuria, Computers \& Electronics in Agric., 66, 38 (2009).

34.M. Mehrubeoglu, K. Orlebeck, M.J. Zemlan, W. Autran, In: Algorithms and Technologies for Multispectral, Hyperspectral, \& Ultraspectral Imagery XXII. M. Velez-Reyes \& D.W. Messinger (Eds.). Proc. SPIE Vol. 9840, 98400D, pp. 1-8 (2016).

35.H. Xiao, W.S. Kim, B. Meng, B., Virology J., 12, 171 (2015).

36.B. Meng, A.R. Rebelo, H. Fisher, J. Gen. Virol., 87, 1725 (2006).

37.A.G. Reynolds, The Grapevine, Viticulture, and Winemaking: A Brief Introduction. In: Grapevine Viruses: Molecular Biology, Diagnostics and Management. B. Meng, G.P. Martelli, D.A. Golino, M. Fuchs: Pp. 3-29. Springer (2017) 


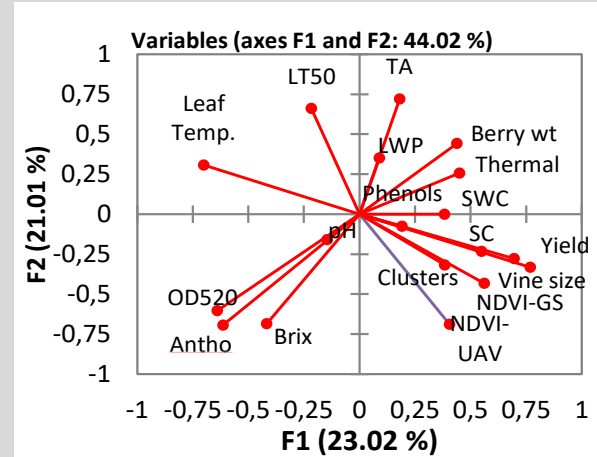

A

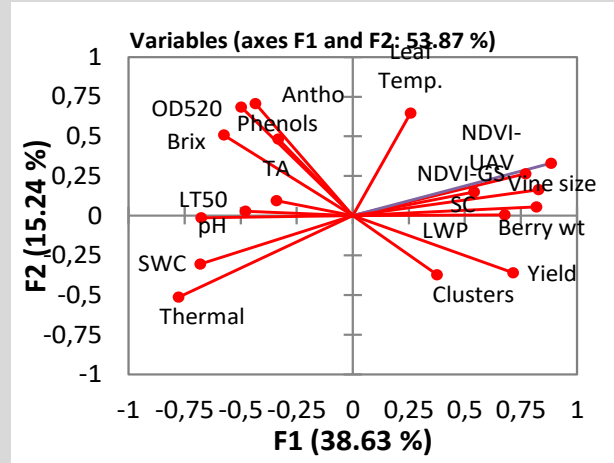

C

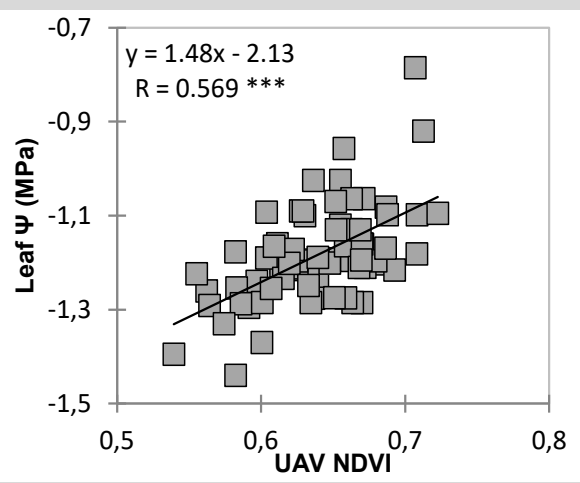

$\mathrm{E}$

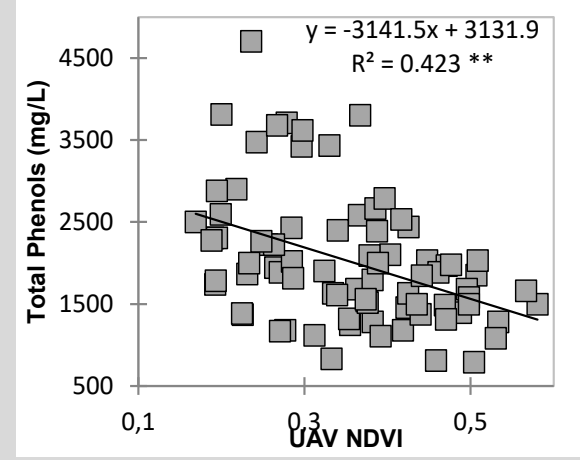

G

Figure 1. A-D: Principal components analysis of four typical Ontario Cabernet franc vineyards, 2016. A: Buis, Virgil, ON; B: Pondview, Virgil, ON; C: Chateau des Charmes, St. Davids, ON; D: George, Vineland, ON. Abbreviations: GS: GreenSeeker; LWP: Leaf water potential; SWC: Soil water content; SC: Stomatal conductance; TA: Titratable acidity. E-H: Relationships between UAV NDVI and viticultural variables in three typical Ontario Cabernet franc vineyards, 2016. E: George, Vineland, ON; F,G: Chateau des Charmes, St. Davids, ON; H: Buis, Virgil, ON.

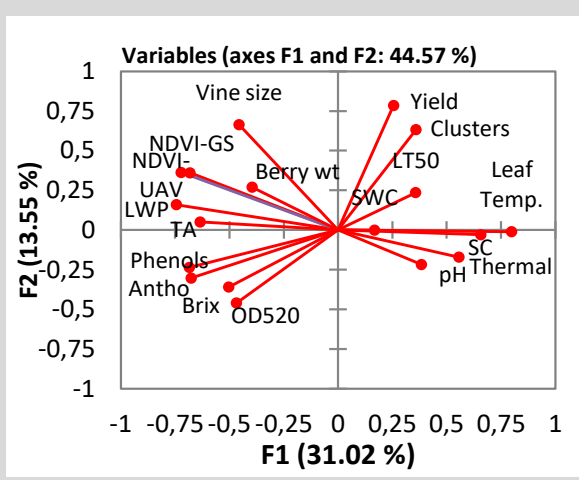

B

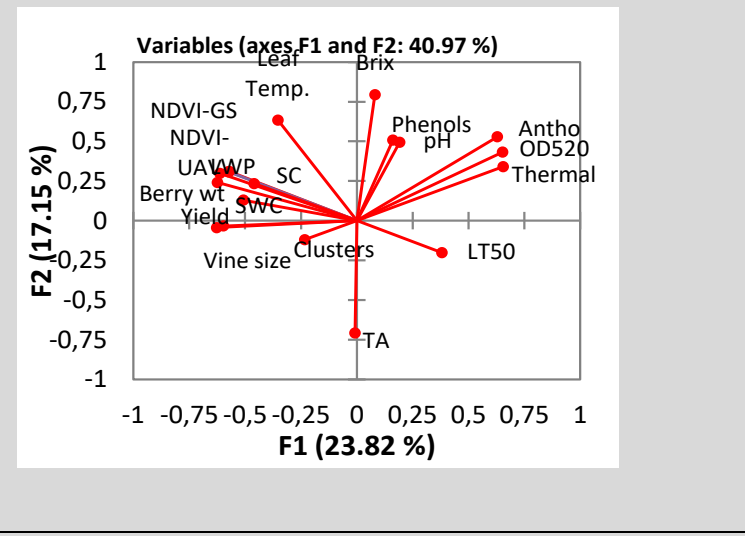

D

$\mathrm{F}$

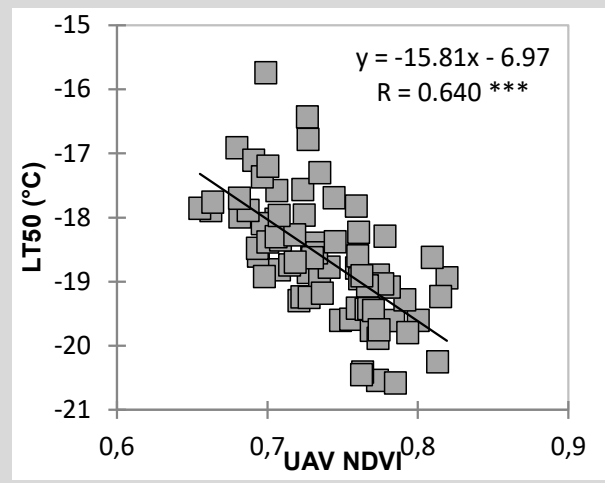

$\mathrm{H}$

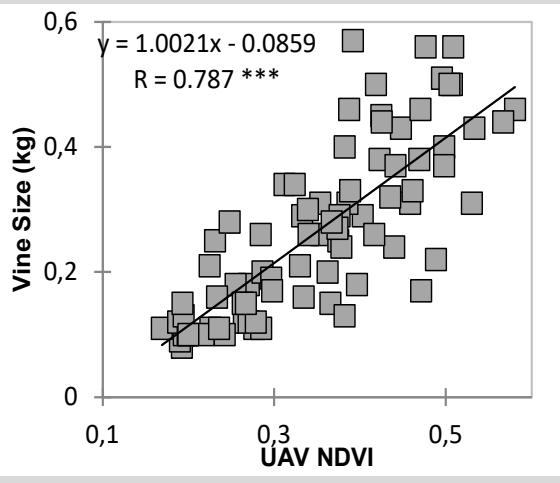




\section{XII ${ }^{\mathrm{TH}}$ International Terroir Congress, Zaragoza 2018}

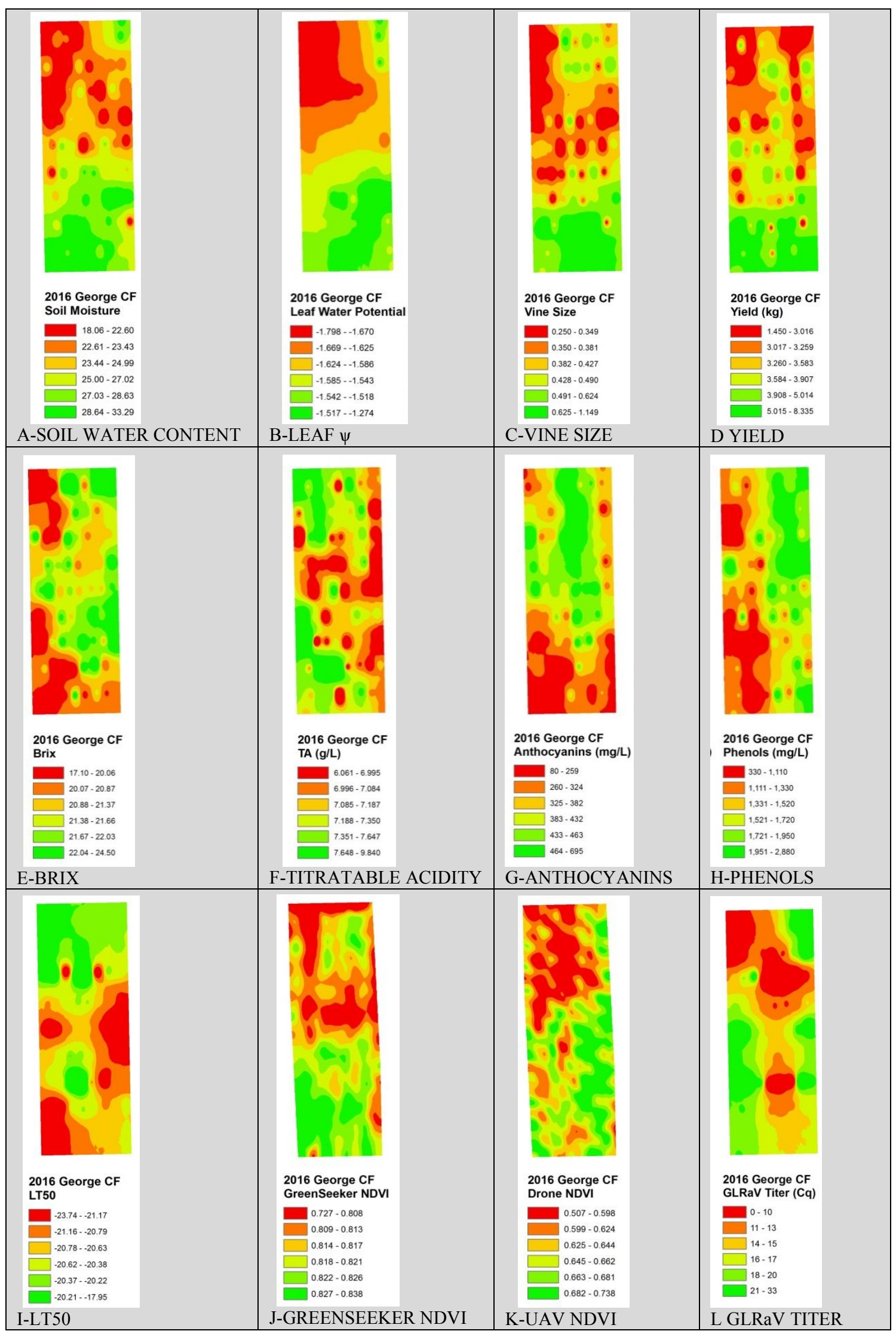

Figure 2. Spatial maps of the George Cabernet franc vineyard, Vineland, ON, 2016. A: Soil water content (\%); B: Leaf water potential (MPa); C: Vine size $(\mathrm{kg})$; D: Yield (kg); E: Brix; F: Titratable acidity (g/L); G: Total anthocyanins (mg/L); H: Total phenols (mg/L); I: LT50 ( $\left.{ }^{\circ} \mathrm{C}\right)$; J: NDVI acquired by GreenSeeker; K: NDVI acquired by UAV; L: GLRaV titer (Cq). 